\title{
The economic benefits to agriculture of a reduction of low-level ozone pollution in The Netherlands
}

\author{
O. J. Kuik
}

Institute for Environmental Studies, Vrije Universiteit, Amsterdam, The Netherlands

J. F. M. Helming

Agricultural Economics Research Institute (LEI-DLO), The Hague, The Netherlands

\section{Dorland and F. A. Spaninks}

Vrije Universiteit, Amsterdam, The Netherlands

Received February 1999, final version received November 1999

\section{Summary}

Low-level ozone pollution affects crop yields adversely. Reduction of ozone pollution would therefore increase crop yields and provide economic benefits to producers and consumers of farm products. This paper assesses the potential magnitude of these benefits for the Netherlands. Exposure-response functions were used to estimate initial yield responses when ozone pollution is reduced to natural background levels. These yield responses were fed into a spatial economic model of the Dutch farm sector, thereby allowing for demand and supply adjustments in all interrelated markets. A novelty in this analysis is the explicit attention to crop-livestock interactions. The annual economic benefits of ozone reduction for producers and consumers of farm products are estimated to be $€ 310$ million, of which $€ 91$ million goes to producers and $€ 219$ million to consumers.

Keywords: low-level ozone pollution, environmental damage assessment, crop yield, crop-livestock substitution, spatial model

JEL classification: Q11, Q25

\section{Introduction}

Air quality may affect crop yields. The economic value of changes in air quality on crop yields is equal to its effect on producers' and consumers' surpluses in the markets for these crops (Freeman, 1993). The surpluses are affected by changes in demand and supply. In the simplest model, an improvement in air quality causes a positive shift in the supply function of individual 
crops. Market prices adjust to establish a new equilibrium of demand and supply. However, in the case of multi-crop farms, farmers may respond to changes in the level of air quality by changing their choice of crops or cultivars and the proportions of the total tillable area used for each crop. After all, not all crops are equally sensitive to air pollution. Yields, and consequently profit margins, of different crops will thus be affected to different degrees. Analysing such changes in cropping pattern requires a model that describes the farmers' cropping choices.

The purpose of our study is to estimate the economic benefits (producer and consumer surplus) of the reduction in ozone damage to crop yields in the Netherlands. ${ }^{1}$

A number of empirical studies have been carried out, mainly in the US during the 1980s, that estimated the value of changes in agricultural production caused by air quality changes. These studies have used either mathematical programming models or econometric models based on microeconomic theory. Examples of crop damage studies are Adams et al. (1982), Howitt et al. (1984), Mjelde et al. (1984), Adams and McCarl (1985), Garcia et al. (1986), Van der Eerden et al. (1988), McCarl et al. (1989) and Tonneijck et al. (1998).

Van der Eerden et al. (1988) estimated the damage caused by air pollution to agriculture in the Netherlands. Exposure-response functions for a number of crops were used to calculate yield reductions caused by actual pollutant concentration levels relative to background levels, i.e. the concentrations that would exist in the absence of any human activities. The main conclusion of Van der Eerden et al. was that the economic damage as a result of air pollution falls disproportionally on consumers, whereas producers see their yield losses (almost) compensated by higher prices. A recent study on the economic impacts of a reduction of crop exposure to the air pollutants nitrogen oxide $\left(\mathrm{NO}_{x}\right)$ and sulphur dioxide $\left(\mathrm{SO}_{2}\right)$ in the Netherlands basically uses the same approach (Tonneijck et al., 1998). A reduction in ambient concentrations of $\mathrm{NO}_{x}$ by 20 per cent and $\mathrm{SO}_{2}$ by 60 per cent is estimated to increase producers' and consumers' surplus by $€ 43$ million and $€ 41$ million, respectively. In their assessment, Tonneijck et al. explicitly assume no adjustments in cropping patterns. They acknowledge that this assumption may not hold in the long run.

One of the first crop damage studies to consider demand and supply responses to changes in air quality is that by Adams et al. (1982), who use price-endogenous mathematical programming to assess the economic damage to 14 annual crops in Southern California caused by ambient ozone exposures. Howitt et al. (1984) expand the analysis to 38 crops and a wider region. Adams et al. compare the results of their assessment with the results that would have been obtained with a simple multiplication technique 
that equates damage to change in yield multiplied by a fixed market price. They find that the simple multiplication technique overestimates the damage by 20 per cent, as a result of its failure to account for mitigating adjustments as well as partially compensating price effects. This failure becomes even more pronounced if one considers only the effect of pollution on producers' surpluses: the simple multiplication technique overestimates producers' surpluses by over 60 per cent (Adams et al., 1982). Howitt et al. basically confirm the results of Adams et al. and point out that the percentage changes in total economic surplus are less than the initial yield changes, indicating the mitigating nature of crop substitution captured in the economic model (Howitt et al., 1984).

Our study builds on these previous assessments and extends the analysis in a number of ways. In comparison with previous European assessments, our model allows for mitigating behaviour of farmers through adjustments in cropping patterns. In that sense our analysis follows the approach taken in the US. A limitation of the US studies is that they focused on the crop sector only. Our analysis explicitly takes the interlinkages between the crop and livestock sectors into account. Apart from these improvements and extensions, our analysis benefits from continuous improvements in air pollution measurement and exposure-response research carried out under European atmospheric and field conditions.

\section{Low-level ozone pollution}

Low-level or tropospheric ozone is formed in air that contains volatile organic compounds (VOCs, such as methane, carbon monoxide and aromatics) and nitrogen oxides $\left(\mathrm{NO}_{x}\right)$ under the influence of sunlight. Chemical reactions in the lower part of the troposphere (the boundary layer) and the free troposphere normally take place in a timeframe of several hours to months. Apart from crop damage, other possible negative effects of elevated ambient ozone levels are to human health and materials. Krupnick et al. (1990), Cody et al. (1992) and Frampton et al. (1995), amongst others, found relations between elevated ozone exposure and an increase in the occurrence of certain health effects, and Sunyer et al. (1996) even found evidence of acute mortality effects. Kucera (1994) and Holland (1998) present results of damage to materials such as rubber, paint and metals.

In the Netherlands, VOCs and $\mathrm{NO}_{x}$ emissions are mainly from mobile sources (transport), stationary sources (industry and households) and agriculture (livestock). Physical damage to crops is a function not only of ozone concentration but also of the exposure pattern. The UN-ECE standard for the long-term critical level of crop exposure to ozone, expressed in AOT40 takes the exposure pattern into account (Kärenlampi and Skärby, 1996). AOT40 is defined as the accumulated exposure to tropospheric ozone over a threshold of 40 parts per billion (p.p.b.). It is calculated as the sum of the differences between the hourly concentration (in p.p.b.) and 40 p.p.b. for each hour that the concentration exceeds 40 p.p.b.. AOT $40_{c}$ is the AOT40 


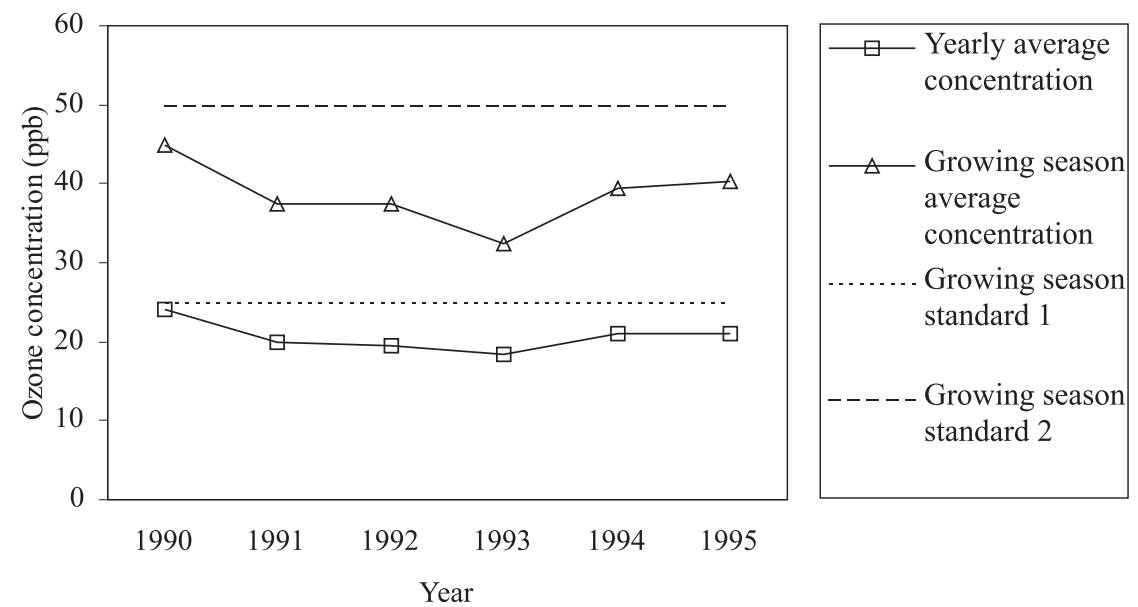

Figure 1. Yearly average and growing season average ozone concentrations between 1990 and 1995 for the Netherlands. The figure includes the Dutch quality standards for the growing season above which some effects (standard 1) and severe effects (standard 2) can be expected (RIVM, 1999).

for the growing season of the crops under study. In the Netherlands AOT40 calculations are based on a growing season from April to August.

Figure 1 shows that average AOT40, values exceeded critical levels in the period 1990-1995, but they do not show a clear upward or downward trend. Therefore, the average AOT $40_{c}$ over that period probably gives a better indication of the potential crop damage caused by average exposure to ozone than the AOT40 cor an individual year. For estimating the crop damage, a map for the average AOT40 c per agricultural area between 1990 and 1995 is made (see Figure 2). This map was created by using a distancerelated weighting interpolation between the measurement sites with the Geographical Information System ArcView. The radius was set at $50 \mathrm{~km}$ and the weight of the measurement sites was set to decrease with the square of the distance. ${ }^{2}$ Finally, AOT40 c was averaged within 14 agricultural areas.

\section{Exposure-response functions}

Jones et al. (1997) carried out a literature review of exposure-response functions for crops. Most functions were found to be based on laboratory experiments, typically carried out under conditions that probably give a limited representation of actual growing conditions, using, for example, single pollutants, particular exposure scenarios and a controlled climate.

2 Different interpolation techniques are used in the literature (De Leeuw and Van Zantvoort, 1995; Posch et al., 1997). According to De Leeuw (personal communication, 1998) the simplified method used in this study gives comparable results. 


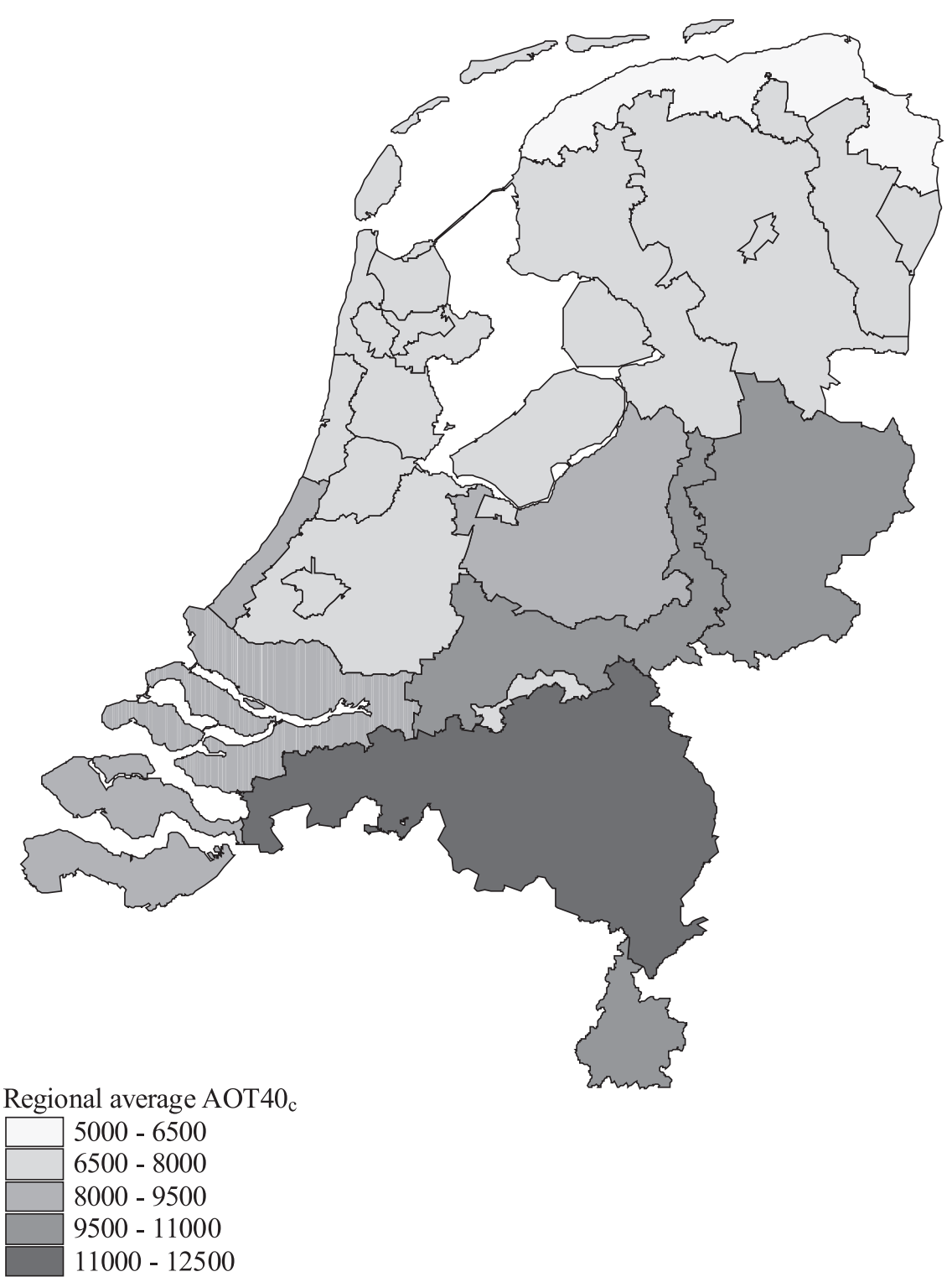

Figure 2. Regionally differentiated average ozone pollution in the period 1990-1995 (AOT40, 14 agricultural areas). Source: LEI.

This limits their usefulness for field conditions. Moreover, functions derived in the US cannot readily be extrapolated to the European situation because these functions were calculated against acute ozone concentrations. In Europe, they are calculated against the accumulated dose. There is evidence that the accumulated dose is more significant in terms of yield loss than 
acute or episodic ozone exposure (Kärenlampi and Skärby, 1996). Therefore, the European functions are used in this study.

For accurate assessments of yield losses against AOT40 the scientific literature recommends the so-called Level II exposure-response model. The important factors to be included in this model are crop species and cultivars, stage of the plant development, soil moisture deficit, vapour pressure deficit and air temperature, susceptibility to pests and pathogens, agrochemical usage, presence of other air pollutants and carbon dioxide concentrations. The data requirements of the Level II approach could not be met in the present study. Therefore, exposure-response functions are based on the so-called Level I approach, which is a rough approximation of the Level II approach but with a far lower data requirement (Kärenlampi and Skärby, 1996).

The most up-to-date Level I based exposure-response relation has been published by Fuhrer in Kärenlampi and Skärby (1996):

$$
\text { per cent yield }=99.7-\alpha\left[\mathrm{O}_{3}\right]
$$

where per cent yield is the relative yield measure, $\left[\mathrm{O}_{3}\right]$ is AOT40 $\mathrm{c}$ and $\alpha$ is a sensitivity parameter (see Table 1).

Fuhrer estimated $\alpha$ for wheat empirically, based on open-top chamber experiments in 10 seasons, six countries and eight cultivars. After carrying out an extensive literature review, Jones et al. (1997) estimated the $\alpha$ values for a wide range of crops on the basis of the relative sensitivity to ozone. These $\alpha$ values (see Table 1) are used in this study. Kärenlampi and Skärby

Table 1. Parameter values for the Fuhrer relations

\begin{tabular}{lll}
\hline Crop & $\alpha$ & Remark \\
\hline Wheat & 1.7 & Indication of degree of risk \\
Maize & Tolerant & \\
Sugar beet & Tolerant & \\
Barley & 1.5 or tolerant & \\
Oats & 0.97 & \\
Sorghum & 0.97 & Trifolium repens probably less sensitive \\
White clover & 2.06 & If farmers are $<100 \%$ efficient, a relative \\
Grasses & 0.97 & proportion of the $\alpha$ value should be used \\
& & \\
Potato & 1.7 & \\
Soybeans and other legumes & 1.7 & \\
Tomato & 1.7 & \\
Leaf vegetables & Tolerant & \\
Fruit trees and grape vines & 1.7 & Relates to sunflower \\
Soft fruit & 0.97 & Assumed tolerant, no data available \\
Flowers & 1.7 & Tolerant \\
Flower bulbs & &
\end{tabular}


argue that these Level I based functions are applicable to the field when nutrient supply and soil moisture are not limiting and when atmospheric mixing conditions are similar to the open-top chamber conditions. The first two conditions are met in normal agricultural practice in the Netherlands. The last condition is probably not met, but it is difficult to assess the error caused by the violation of this condition.

The Fuhrer function and the $\alpha$ values in Table 1 are used for estimating yield increases as a result of a reduction of ambient ozone levels from current levels (see Figure 2) to the natural background concentration of 20 p.p.b. (which never exceeds the threshold level of 40 p.p.b., thus AOT40 $=0$ ).

\section{The economic model}

The yield increases that are predicted by the Fuhrer function are fed, as exogenous shocks, into a spatial economic model of the Dutch farm sector: the Dutch Regionalised Agricultural Model (DRAM). DRAM is used because it takes account of endogenous price effects, interdependences between livestock and cropping activities, regional interdependences and differential impacts on producers and consumers. The objective function of DRAM maximises total economic surplus of agriculture, i.e. the sum of producers' surplus (gross margins) and consumers' surplus. A detailed description of DRAM can be found in Helming (1999).

DRAM distinguishes between 14 regions, 22 agricultural products marketed outside the agricultural sector and three intermediate products consumed inside the sector (roughage, animal manure and young stock).

Individual inputs and outputs at the farm level are aggregated to the regional level: 'the regional farm'. A graphical representation of DRAM is presented in Figure 3.

DRAM uses linear price-dependent demand functions. Own price elasticities are derived from Tonneijck et al. (1998) and Witzke and Britz (1998). ${ }^{3}$ Demand for those agricultural commodities that are heavily regulated by the Common Agricultural Policy (cereals, starch potatoes, milk and beef) is assumed to be perfectly elastic. Furthermore, national quotas are implemented for the output of sugar beet and starch potatoes. It is assumed that markets clear every year. The model does not include substitution effects in demand for agricultural products marketed outside the agricultural sector.

The model assumes exogenous prices for inputs purchased outside the sector. Own and cross price elasticities of intermediate inputs, however, can be derived from changes in shadow prices on the balances of regional demand and supply (Helming, 1999). The advantage of this approach is that direct econometric estimation of own and cross price elasticities of intermediates can be avoided.

3 These are elasticities of total demand (domestic and export). If output increases affect the share of export demand in total demand, the price changes that are calculated in this paper may be somewhat overstated, as export demand elasticities are likely to be greater than elasticities of domestic demand. We believe that this error is minor in the present calculations, however. 


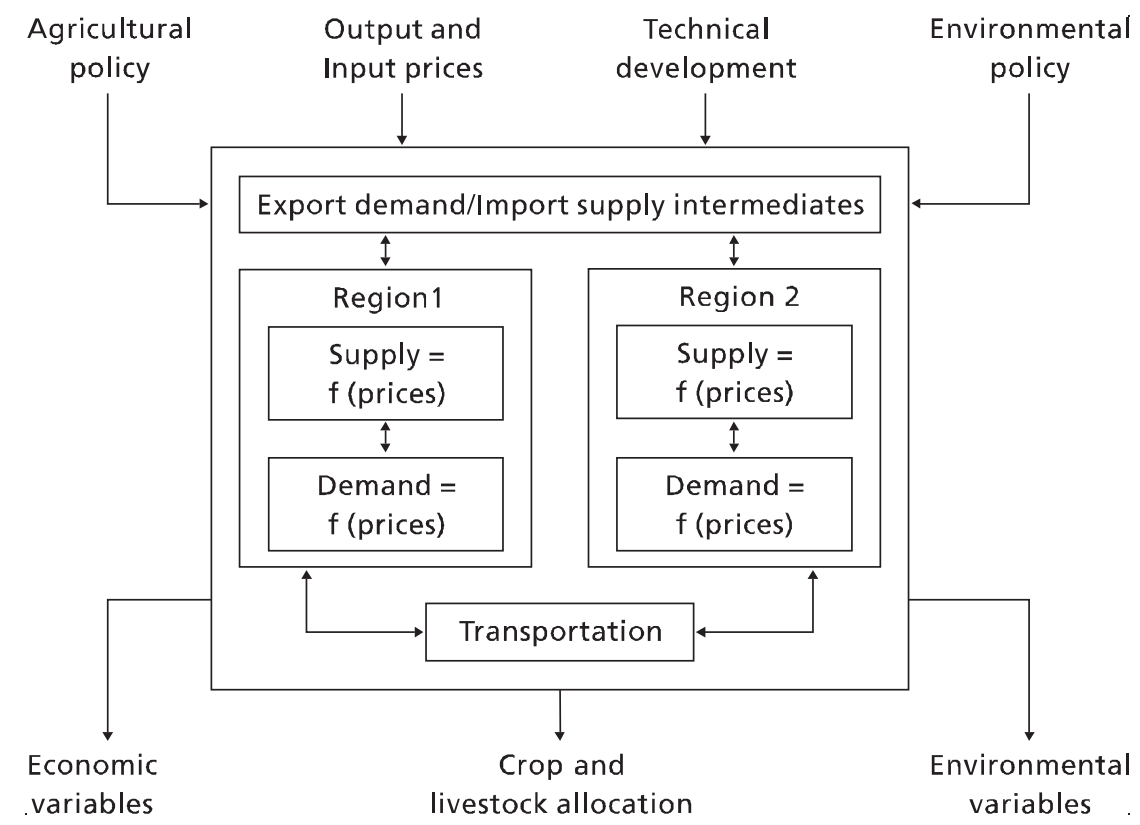

Figure 3. A graphical representation of DRAM.

A special feature of DRAM compared with other sector models is that it takes into account interdependences between livestock and cropping activities through endogenous prices of roughage, young stock and animal manure (Helming, 1999). Through technical restrictions and existing legislation with respect to the application of animal manure, regional manure prices might be relatively important and interact with the effects of reducing ozone levels on crop production and allocation. Reducing ozone levels affecting crop yields differently could, for example, increase the incentive to grow cereals. However, crops are not homogeneous with respect to demand for animal manure. For example, much more animal manure can be applied to maize than to cereals and hence, with relatively high manure prices for the producer of animal manure, there is also a strong incentive to grow maize.

Variable costs of agricultural activities in crop and animal production are represented by quadratic variable cost functions: the cost of a given activity in a region is assumed to increase as the level of that activity is expanded in that region. This specification is in line with the empirical observation of large variations in costs per hectare. Howitt (1995) explains this by assuming differences in soil suitability. In line with this assumption it can be argued that average costs will rise with output, as less productive land is cultivated last. Another argument to explain rising costs would be differences in management quality at the farm or regional level.

The parameters of the quadratic cost functions are calculated from exogenous prices and quantities of purchased inputs and shadow values on actual regional activity levels observed in the period 1993-1994 to 1995-1996. 
These shadow values are obtained from an initial model run with activities restricted to actual or observed figures. This approach is called positive mathematical programming (PMP) and calibrates the model exactly to the observed figures without any loss of flexibility. The PMP approach thus combines some of the advantages of the mathematical programming and econometric approaches. More detailed information on PMP can be found in Horner et al. (1992) and Howitt (1995).

PMP is a theoretically consistent approach to make mathematical programming models better capable of reproducing observed levels of activities. Therefore PMP offers a solution to the problem of limited empirical knowledge about medium- and long-term supply behaviour. However, the problem with the PMP approach is that allocation and supplies are not explained by the PMP coefficients themselves, as PMP coefficients are dependent upon many things and constant during the simulations. According to Jonasson and Apland (1997), the use of PMP compensates for a poor model of the actual technology being used on the farm. The first-best solution would be to include more data in the model to make the PMP coefficients as small as possible. However, data explaining allocation and supplies, such as information on technical constraints at the farm level, investment and risk behaviour, primary factor costs and management capacities of farmers are scarce and very incomplete.

Given these problems, how well does DRAM perform? A previous version of DRAM was used to assess the effects of an environmental policy switch in the agricultural sector in the Netherlands. The evaluated scenario is described in Helming (1997). Among other things the policy switch includes levies on phosphate surpluses. A reduction in farmers' income of about 370 million guilders was estimated with DRAM. In another Dutch study, based on detailed farm-level models, a reduction in farmers' income of between 275 and 310 million guilders was found (de Hoop et al., 1995). A large part of the difference in outcome between the studies can be explained by the difference in the models' predictions of the total levies paid by farmers on phosphate surpluses. The farm-level models included many more management options on grassland to reduce phosphate surpluses and associated levy payments, whereas the interactions through markets are missing (Helming, 1999). Given the complexity of the policy switch under investigation, it can be concluded that the calculated income effects were comparable within the range of uncertainty, giving confidence in DRAM's capabilities.

\section{Results}

DRAM was used to calculate the economic consequences of the reduction of the ambient ozone levels to natural background levels. ${ }^{4}$ Table 2 presents the

4 This represents a decrease in current levels of growing season average ozone concentrations of approximately 50 per cent (from 40 to 20 p.p.b.). It should be noted that at natural background levels $\mathrm{AOT} 40_{\mathrm{c}}=0$. 
Table 2. Impacts of $\mathrm{O}_{3}$ reduction on yields, cropping plan and market prices of selected crops (in percentage change)

\begin{tabular}{lccc}
\hline Crop & Change in yield/ha & Change in crop area & Change in market price \\
\hline Cereals & 13.9 & 7 & 0 \\
Pulses & 19.3 & 30 & 0 \\
Sugar beet & 0.0 & -1 & 0 \\
Fodder beet & 0.0 & -8 & 4 \\
Ware potato & 18.5 & -8 & -26 \\
Seed potato & 13.9 & -2 & -15 \\
Starch potato & 14.7 & -13 & 0 \\
Onion & 17.2 & 3 & -11 \\
Other arable & 8.1 & 13 & 0 \\
Flower bulb & 0.0 & 1 & -0 \\
Vegetables I $^{\mathrm{a}}$ & 11.2 & 1 & -10 \\
Vegetables II $^{\mathrm{b}}$ & 18.5 & -4 & -21 \\
Vegetables III $^{\mathrm{c}}$ & 19.9 & -5 & -16 \\
Grassland $^{\text {Green maize }}$ & 9.3 & 1 & -1 \\
\hline
\end{tabular}

${ }^{\mathrm{a}}$ Intensively grown, such as leek, sprout, cauliflower.

${ }^{\mathrm{b}}$ Extensively grown, winter carrot.

${ }^{\mathrm{c}}$ Extensively grown, other.

percentage changes in yields, crop areas and market prices for a selected number of crops as a consequence of the reduction in ambient ozone levels.

The average yield increases in Table 2 are a function of regional ozone levels and the geographical distribution of crops in the initial (polluted) situation, and the sensitivity of the crops to ozone pollution (the $\alpha$ values). Some of the calculated yield increases are rather large: almost 20 per cent for pulses and certain intensively grown vegetables, and some 14-19 per cent for potatoes. $^{5}$

The yield increases affect prices and cropping patterns. Because of DRAM's downward sloping demand curves for a number of products, market prices tend to fall as a consequence of yield increases. To some extent, this tendency is counteracted by changes in cropping pattern. The magnitude of crop area change is directly related to the price flexibility $(\% \Delta P / \% \Delta Q)$ of the demand function (Howitt et al., 1984). Demand functions of ware potatoes and seed potatoes are characterised by high price flexibilities. As was also found by Howitt et al. (1984), as a result of the improvement in air quality, production increases, price decreases and crop area decreases. This pattern does not hold for crops with relatively low price flexibilities. The crop area of crops with a

5 As was discussed in Section 3, the yield increases can be realised only when nutrient supply and soil moisture are not limiting. We believe this is the case for the Netherlands. 
relatively low price flexibility will expand. Table 2 shows the equilibrium effects on prices and crop areas cultivated. Changes in cultivated areas range from +30 per cent for pulses to -5 per cent for green maize. The decrease in land allocated to starch potato is explained by the strong yield increase per hectare and the national quota. Area changes of this order of magnitude were also reported in the US studies discussed above. ${ }^{6}$ Price effects range from +4 per cent for fodder beet to -26 per cent for ware potatoes.

The impact on intensive livestock through changes in the costs of manure disposal is negligible, at least under the manure legislation in our base period.

The calculated price and quantity effects affect producer and consumer welfare. As a result of a reduction of ambient ozone levels, producer surplus increases by $€ 91$ million $^{7}$ ( 1.5 per cent).

Figure 4 shows that the regional distribution of changes in producer surplus is skewed. Some of the most productive arable regions in the Netherlands (southern sea clay area and the IJsselmeer polders) are likely to see a reduction in farmers' income as a result of a reduction in ambient ozone levels, whereas regions with a large share of pasture (roughage), starch potatoes and 'other' arable crops are likely to experience increases. The ultimate regional impact on producer surpluses has very little relation to the original regional distribution of ambient ozone levels and the consequent reductions of these levels.

Table 3 shows sectoral changes in economic surpluses. Producers compensate for lower prices in the arable sector by shifting their cropping activities towards crops with a relatively low price flexibility of demand. Yield increases on grassland and the resulting substitution between maize and grassland on the one hand, and also between maize and grassland and arable crops on the other hand, lead to important total cost savings in the cattle farming sector. ${ }^{8}$ The resulting increase in producer surplus in this sector is $€ 67$ million (2.0 per cent).

Consumers gain from lower output prices. Consumer surplus increases by $€ 219$ million (2.2 per cent) (see Table 3 ).

The total calculated increase in economic surplus is $€ 310$ million. This is similar to the result of Van der Eerden et al. (1988). Those workers assessed total crop damage caused by ozone, sulphur dioxide and hydrogen fluoride at $€ 403$ million, ${ }^{9}$ of which 70 per cent (in yield effect) is supposed to be due to ozone pollution. The similarity of the final results is largely coincidental; it hides differences in exposure-response functions, crop coverage and economic assumptions. The most interesting difference between our analysis

6 Howitt et al. (1984), for example, found area changes between -13.7 per cent (celery) and +0.4 per cent (wheat).

7 Euro values are converted from 1995 Dutch Guilders.

8 The cattle farming sector is an aggregate of the beef, milk and roughage (grasses and maize) production sectors that are distinguished in DRAM. The producers' surplus from the beef and milk production sectors decreases, but this is more than offset by an increase in the producers' surplus from roughage production.

9 Converted to ECU 1995 prices by Markandya and Pavan (1999). 


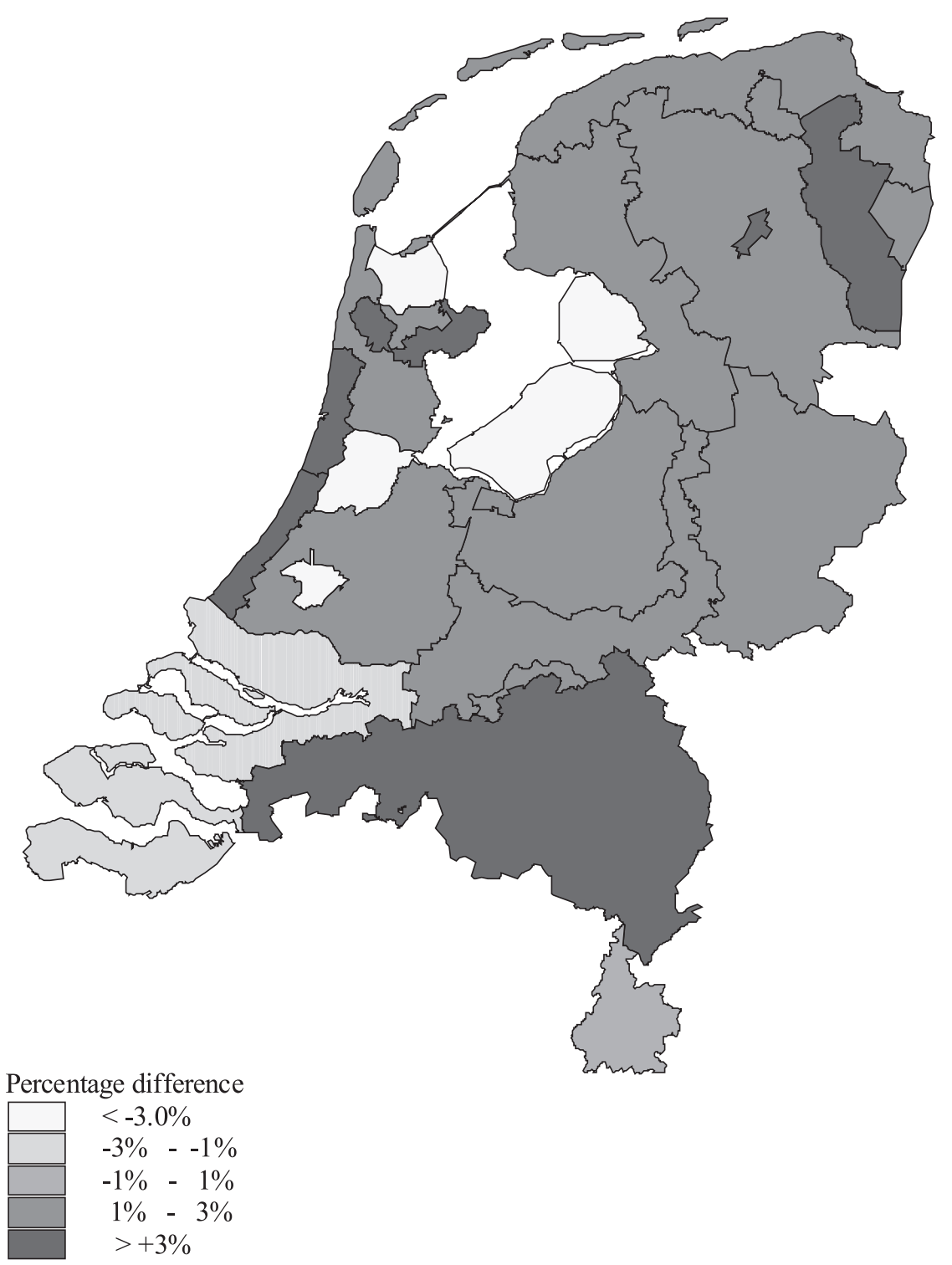

Figure 4. Regionally differentiated impacts of ozone reduction on producer surpluses (percentages, 14 agricultural areas). Source: LEI.

and that of Van der Eerden et al. is the distribution of the benefits. The results of Van der Eerden et al. indicate that only 9 per cent of the monetary benefits of ozone reduction would accrue to farmers, whereas 91 per cent would accrue to consumers. Because of our assumption that farmers can adjust their cropping pattern to changes in air quality and because of the crop-livestock 
Table 3. Sectoral changes in economic surplus

\begin{tabular}{lcc}
\hline Sector & Difference (million $€)$ & $\%$ \\
\hline Cattle farming & 67 & 2.0 \\
Intensive livestock farming & 0 & 0.0 \\
Arable & 24 & 1.6 \\
Total producer surplus & 91 & 1.5 \\
Total consumer surplus & 219 & 2.2 \\
\hline
\end{tabular}

interactions, our analysis suggests that farmers are able to reap a substantially larger share of the benefits (about 30 per cent).

The calculated increase in consumer and producer surpluses represents the maximum obtainable economic benefit of ozone reduction to the agricultural sector. The reduction in ambient ozone levels that is used in this study is not based on any actual or proposed emission reduction policy. However, some policy perspective is provided by a recent UN-ECE proposal to set ozone standards at an AOT40 c level of 3000 (Kärenlampi and Skärby, 1996), which roughly means a 66 per cent decrease in the average measured AOT40 $0_{\mathrm{c}}$ level in the Netherlands between 1990 and 1995.

\section{Conclusions}

This study assesses the economic benefits of a reduction of the ambient level of ozone to the agricultural sector. For the correct interpretation of the results it should be realised that ozone control also has benefits outside the agricultural sector, especially related to human health. The present study does not address the complex issue of identifying and costing the measures that are necessary to achieve the specified reduction in ambient ozone levels and it can therefore make no suggestion as to the optimal level of ozone control.

For the purpose of the assessment a physical exposure response model was coupled to a regionalised economic model of the Dutch agricultural sector. Both the physical model and the economic model can be improved upon. The physical model used in this study is an approximation of the recommended Level II model, which could not be used because of data constraints. A shortcoming of the economic model may be its grouping of individual farms into 'regional' farms, thereby losing sight of possibly strong heterogeneity among individual farms and activities. Fortunately, in a comparison between the present model and detailed farm-level models in the context of the evaluation of the introduction of phosphate levies the present model performed fairly well, suggesting that the 'aggregation bias' may be of limited empirical importance.

The results of the assessment confirm two findings of previous studies. The economic benefits to the agricultural sector of a reduction of ambient ozone levels are likely to be significant, and the larger part of these benefits will be 
passed on to consumers of farm products. Contrary to previous European (Dutch) studies, the study does find a substantial potential for farmers to adjust their activities, especially cropping plans, to changes in ambient air quality. A new and somewhat surprising result of the present study is the relatively large increase in producer surplus in the cattle farming sector. The two mechanisms responsible for the linkages between the crop sector and the cattle farming sector are changes in roughage yields (and prices) and changes in the costs of animal manure disposal. In the present scenario, the costs of manure disposal are relatively unaffected. The major effect is yield increases on grassland that lead to economic surpluses in the roughage sector, which is a subsector of the cattle farming sector.

Finally, the study suggests that the regional distribution of farmers' benefits from a reduction of ambient ozone levels is skewed and has very little relation to the original regional distribution of ambient ozone levels.

\section{Acknowledgements}

The authors gratefully acknowledge the financial support of the EU Commission, DG XII (ENVCT96-0285). H. Jones and M. Hornung of the Institute for Terrestrial Ecology, Grange-overSands, UK, have provided valuable input regarding the use and reliability of crop exposureresponse functions. We also thank A. Y. Mahieu of LEI for her work on the maps. Finally, the authors thank three anonymous referees for their helpful comments on an earlier draft of this paper.

\section{References}

Adams, R. M. and McCarl, B. A. (1985). Assessing the benefits of alternative ozone standards on agriculture: the role of response information. Journal of Environmental Economics and Management 12: 264-276.

Adams, R. M., Crocker, T. D. and Thanavibulchai, N. (1982). An economic assessment of air pollution to selected annual crops in Southern California. Journal of Environmental Economics and Management 9: 42-58.

Cody, R. P., Weisel, C. L., Birnbaum, G. and Lioy, P. J. (1992). The effect of ozone associated with summertime photo-chemical smog on the frequency of asthma visits to hospital emergency departments. Environmental Research 58: 184-194.

de Hoop, D. W., Daatselaar, C. H. G., Hennen, W. H. G. J., Hoste, R., Wien, J. F. F. and Verhoog, A. D. (1995). Sociaal-economische gevolgen van de Integrale Notitie Mest- en Ammoniakbeleid. The Hague: Agricultural Economics Research Institute (LEI-DLO).

de Leeuw, F. A. A. M. and E. D. G. van Zantvoort (1995). Mapping of exceedances of ozone critical levels for crops and forests in the Netherlands, preliminary results. Report number 722401 011. Bilthoven: National Institute of Public Health and the Environment (RIVM).

Frampton, M. W., Morrow, P. E., Cox, C., Levy, P. C., Condemi, J. J., Speers, D., Gibb, F. R. and Utell, M. J. (1995). Sulfuric acid aerosol followed by ozone exposure in healthy and asthmatic subjects. Environmental Research 69: 1-14.

Freeman, A. M. (1993). The Measurement of Environmental and Resource Values: Theory and Methods. Washington, DC: Resources for the Future.

Garcia, P., Dixon, B. L., Mjelde, J. W. and Adams, R. M. (1986). Measuring the benefits of environmental change using a duality approach: the case of ozone and Illinois cash grain farms. Journal of Environmental Economics and Management 13: 69-80. 
Helming, J. F. M. (1997). Impacts of manure policies for the Netherlands. In F. Brouwer and W. Kleinhanss (eds), The Implementation of Nitrate Policies in Europe: Processes of Change in Environmental Policy and Agriculture. Landwirtschaft und Umwelt. Kiel: Vauk, 235-251.

Helming, J. F. M. (1999). Effects of nitrogen input and nitrogen surplus taxes in Dutch agriculture. Cahiers d'Economie et Sociologie Rurales 49: 5-31.

Holland, M. (1998). The effects of ozone on materials. Report AEAT-4401. Culham, UK: EA Technology plc, National Environmental Technology Centre.

Horner, G. L., Corman, J., Howitt, R. E., Carter, C. A. and MacGregor, R. J. (1992). The Canadian regional agriculture model, structure, operation and development. Technical Report 1/92. Agriculture and Agri-Food Canada. Ottawa, Ontario, Canada.

Howitt, R. E. (1995). Positive mathematical programming. American Journal of Agricultural Economics 77: 329-342.

Howitt, R. E., Gossard, T. W. and Adams, R. M. (1984). Effects of alternative ozone concentrations and response data on economic assessments: the case of California crops. Journal of the Air Pollution Control Association 34: 1122-1127.

Jonasson, L. and Apland, J. (1997). Frontier technology and inefficiencies in programming sector models: an application to Swedish agriculture. European Review of Agricultural Economics 24: 109-131.

Jones, H. E., Howson, G., Rosengren-Brinck, U. and Hornung, M. (1997). Review of the effects of air pollutants on agricultural crops, forestry and natural vegetation. Report for ExternE Project. Brussels: European Commission.

Kärenlampi, L. and Skärby, L. (1996). Critical levels for ozone: testing and finalizing the concepts. UN-ECE Workshop Report. Kuopio, Finland: Department of Ecology and Environmental Science, University of Kuopio.

Krupnick, A. J., Harrington, W. and Ostro, B. (1990). Ambient ozone and acute health effects: evidence from daily data. Journal of Environmental Economics and Management 18: $1-18$.

Kucera, V. (1994). The UN ECE international cooperative programme on effects on materials, including historic and cultural monuments, report to the working group on effects within the UN ECE in Geneva. Stockholm: Swedish Corrosion Institute, 1994.

Markandya, A. and Pavan, M. (eds) (1999). Green Accounting in Europe-Four Case Studies. Dordrecht: Kluwer Academic.

McCarl, B., Brown, D., Adams, R. and Pheasant, J. (1989). Linking farm and sector models in spatial equilibrium analysis: an application to ozone standards as they affect Corn Belt agriculture. In W. C. Labys, T. Takayama and N. D. Uri (eds), Quantitative Methods for Market-Oriented Economic Analysis over Space and Time. Aldershot: AshgateAvebury.

Mjelde, J. W., Adams, R. M., Dixon, B. L. and Garcia, P. (1984). Using farmers' actions to measure crop loss due to air pollution. Journal of the Air Pollution Control Association 31(4): 360-364.

Posch, M., Hettelingh, J. P., de Smet, P. A. M. and Downing, R. J. (1997). Convention on Long-Range Transboundary Air Pollution of the United Nations Economic Commission for Europe: Calculation and mapping of critical thresholds in Europe. Report nuber RIVM 259101007. Bilthoven: National Institute of Public Health and the Environment (RIVM).

RIVM (1999). Luchtkwaliteit—Jaaroverzicht 1997. Bilthoven, Netherlands: Rijksinstituut voor Volksgezondheid en Milieu (RIVM). 
Sunyer, J., Castellsague, J., Saez, M., Tobias, A. and Anto, J. M. (1996). Air pollution and mortality in Barcelona. Journal of Epidemiology and Community Health 50(Suppl. 1): S76-S80.

Tonneijck, A. E. G., van der Eerden, L. J., Wijnands, J. H. M., Bunte, F. H. J., Bremmer, J. and Hoogeveen, M. W. (1998). Economische Aspecten van het Effect van Luchtverontreiniging op de Gewasteelt in Nederland (Economic aspects of the effect of air pollution on crop production in the Netherlands). Report 90. Wageningen: AB-DLO.

Van der Eerden, L. J., Tonneijck, A. E. G. and Wijnands, J. H. M. (1988). Crop losses due to air pollution in the Netherlands. Environmental Pollution 53: 365-376.

Witzke, H. P. and Britz, W. (1998). A maximum entropy approach to the calibration of a highly differentiated demand system. CAPRI Working Paper 98-06.

URL: www.agp.uni-bonn.de/agpo/rsrch/capri/wrkpap_e.htm

Corresponding author: Onno Kuik, IVM-VU, De Boelelaan 1115, 1081 HV Amsterdam, The Netherlands. E-mail: onno.kuik@ivm.vu.nl 